\title{
Penerapan Tema "The Next Level of Comfort" Pada Perancangan Interior Hotel Doubletree
}

\author{
Emmanuella Suryady ${ }^{1}$, Noeratri Andanwerti ${ }^{2}$, Silvia Meliana ${ }^{3}$ \\ ${ }^{1}$ Program Studi Desain Interior, ${ }^{2,3}$ Fakultas Seni Rupa dan Desain, Universitas Tarumanagara, Jakarta \\ emmanuella.615170008@stu.untar.ac.id, noeratria@fsrd.untar.ac.id, silvia.meliana@gmail.com
}

\begin{abstract}
Perancangan sebuah hotel perlu mempertimbangkan dua aspek utama, yaitu efisiensi dan kenyamanan. Dua aspek ini secara keseluruhan akan mempengaruhi keputusan sebuah rancangan hotel dengan melihat kepentingan konsumen hotel yang menjadi sasaran hotel tersebut. Pada akhirnya hal ini akan berdampak pada lahirnya rancangan berbagai jenis hotel yang berbeda sesuai jenis target pasarnya. Perancangan hotel ini bertujuan untuk menjelaskan betapa pentingnya peran interior dalam kehidupan manusia sebagai pengguna. Hasil analisis baik makro, mikro, pengguna, fasilitas, besaran ruang, hubungan ruang, zoning blocking, sirkulasi, dan sampai citra diperlukan untuk menentukan peningkatan dalam perancangan interior Hotel Doubletree. Dari hasil analisis inilah muncul tema "The Next Level of Comfort" yang menjadi patokan untuk peningkatan perancangan interior Hotel Doubletree di Jakarta. Peningkatan dilakukan dengan cara mengubah material yang lebih tahan lama dan memiliki kualitas yang baik, furniture yang multifungsional, dan suasana yang membuat baik tamu maupun pekerja hotel aman dan nyaman. Konsep pada setiap ruang disesuaikan dengan kebutuhan dan kenyamanan penggunanya agar memaksimalkan kualitas dan kenyamanan dari peningkatan perancangan hotel Doubletree.
\end{abstract}

Kata Kunci: Citra, Desain Interior, Hotel, Peningkatan, Perancangan.

\section{PENDAHULUAN}

\subsection{Latar Belakang}

Kota merupakan tumpuan masyarakat Indonesia sebagai tempat harapan dan cita - cita untuk memperoleh pekerjaan. Kota besar dan metropolitan bagaikan magnet yang mempunyai daya tarik kuat bagi banyak orang. Perkembangan kota di era sekarang ini sangat cepat namun banyak orang yang membutuhkan ketenangan di penatnya kesibukan kota. Jakarta tidak luput dari bahaya penyebaran COVID-19. Dengan imbauan physical distancing, sebagai control terhadap penyebaran virus. Saat ini, tentu yang bisa kita lakukan adalah mengurangi kontak dengan banyak orang untuk bersama menekan laju penyebaran wabah COVID-19. Salah satu yang dapat mempengaruhi social distancing adalah 
interior sebuah bangunan / ruangan juga dapat berperan di era masa kini.

Hotel adalah jenis akomodasi yang menggunakan sebagian atau seluruh bagian untuk memberikan jasa pelayanan penginapan, penyedia makanan dan minuman, serta jasa lain bagi masyarakat umum dan dikelola secara komersial. Dengan berubahnya gaya hidup, fungsi hotel mengalami perubahan, tidak sekadar sebagai tempat menginap, tetapi juga untuk mengadakan rapat, pertemuan, resepsi pernikahan, seminar, pameran, bahkan pertunjukan. Perancangan sebuah hotel perlu mempertimbangkan dua aspek utama, yaitu efisiensi dan kenyamanan. Dua aspek ini secara keseluruhan akan mempengaruhi keputusan sebuah rancangan hotel dengan melihat kepentingan konsumen hotel yang menjadi sasaran hotel tersebut. Pada akhirnya hal ini akan berdampak pada lahirnya rancangan berbagai jenis hotel yang berbeda sesuai jenis target pasarnya. Perancangan ini bertujuan untuk menjelaskan betapa pentingnya peran interior dalam kehidupan manusia sebagai pengguna.

(Putra, 2020)

\subsection{TUJUAN PERANCANGAN}

1. Memaksimalkan kenyamanan dan keamanan bagi para pengguna hotel Doubletree.

2. Menciptakan utilitas interior hotel Doubletree yang aman, nyaman, dan sehat bagi pengguna.

3. Merancangan interior hotel dengan memenuhi standard protocol kesehatan yang ada.

4. Menciptakan sirkulasi yang aman dan nyaman bagi para pengguna hotel Doubletree.

5. Merancang interior hotel Doubletree yang sesuai dengan citra Doubletree.

\subsection{RUANG LINGKUP PERANCANGAN}

Perancangan interior Hotel Doubletree ditekankan pada kamar hotel tipe Suite Lounge King, restoran yang biasanya menjadi pusat para pengunjung, serta meeting room untuk para pengunjung dengan tujuan bisnis.

\section{METODE}

Metode yang akan digunakan dalam perancangan ini adalah metode kualitatif. Metode kualitatif merupakan metode 
penelitian yang bersifat deskriptif dan induktif. Pada metode ini, data penelitian diperoleh dari kegiatan yang berlangsung di lapangan dan studi literatur tentang DoubleTree.

- Metode Pengumpulan Data

Berikut ini dengan menggunakan metode kualitatif, pengumpulan data dapat dilakukan dengan beberapa cara, yaitu:

1. Studi Literatur

Pengumpulan informasi yang berhubungan dengan definisi, fungsi, jenis dan semua hal yang berkaitan dengan informasi yang dibutuhkan untuk perancangan hotel

DoubleTree.

2. Survey Lapangan

Survey yang dilakukan untuk mendapatkan informasi yang dibutuhkan berkaitan dengan kondisi tempat. Data yang dibutuhkan mencakup dokumentasi lokasi, kegiatan yang berlangsung serta fasilitas-fasilitas yang dibutuhkan di dalamnya.

- Metode Perancangan

Setelah pengumpulan data, selanjutnya adalah menganalisis masalah yang terdapat di Hotel Doubletree. Setelah itu dilanjutkan dengan membuat program ruang yang terdiri dari diagram matriks, total kebutuhan ruang, bubble diagram dan hubungan antar ruang. Selanjutnya adalah menentukan konsep desain. Perancangan interior selanjutnya adalah konsep yang dimulai dari pembuatan layout. Layout dibuat berdasarkan kebutuhan fasilitas dan aktivitas yang disesuaikan dengan data-data yang telah didapatkan. Gambar kerja lain meliputi floor and wall plan, ceiling plan, furniture plan, mechanical and electrical plan, potongan, tampak dan perspektif dikerjakan setelah pembuatan layout selesai. Setelah gambar kerja, untuk realisasi perancangan dapat dilanjutkan dengan pembuatan gambar presentasi meliputi layout 
furniture, tampak, potongan, perspektif berwarna, serta skematik material dan warna yang akan digunakan.

\section{HASIL DAN PEMBAHASAN}

\subsection{ANALISA}

DoubleTree by Hilton adalah sebuah jaringan hotel asal Amerika dan merupakan bagian dari Hilton Worldwide. Salah satu ciri khas DoubleTree adalah kukis coklat yang mulai disajikan pada awal dekade 1980-an untuk penginap naratama dan nratetama, namun kini disajikan pada semua penginap. Kukis ini dibuat oleh Christie Cookie Company sejak 30 tahun lalu. Visi dari Doubletree adalah "To Fill Earth with the Light and Warmth of Hospitality" dan misi dari Doubletree adalah :

- To be the Preminent Global Hospitality Company

- The first choice of Guests, Team Member and Owner Alike.

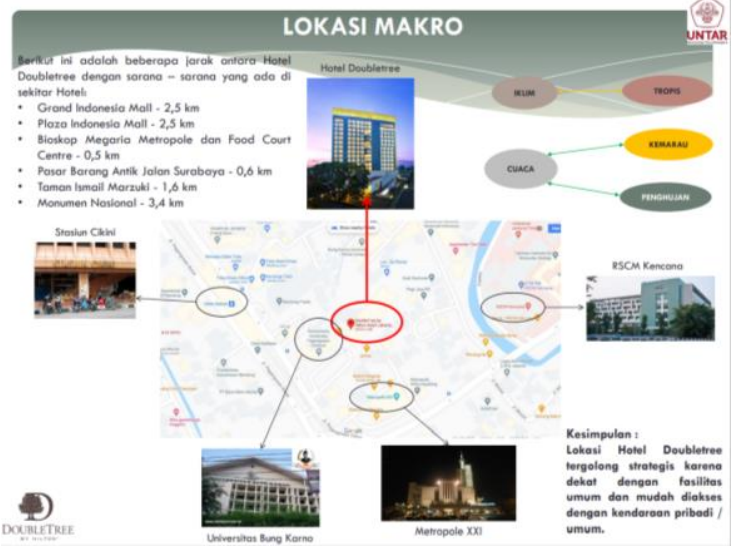

Gambar 1.1 Analisis Makro Hotel Doubletree

Hotel Doubletree berada pada iklim tropis, yang memiliki cuaca kemarau dan penghujan. Hotel Doubletree juga dikelilingi oleh banyak fasilitas umum dan mudah diakses oleh kendaraan baik umum atau pribadi. Maka, kesimpulannya, lokasi hotel Doubletree tergolong strategis.

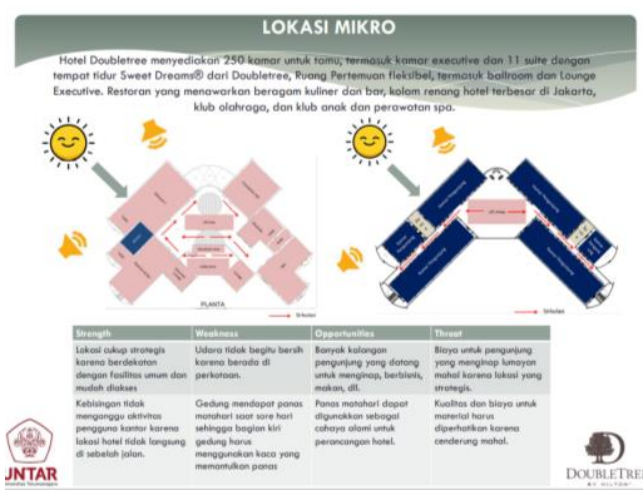

Gambar 1.2 Analisis Mikro Hotel Doubletree

Analisis SWOT pada hotel

Doubletree:

\begin{tabular}{|l|l|l|l|}
\hline Streng & Weakn & Opportu & Threat \\
\hline
\end{tabular}




\begin{tabular}{|c|c|c|c|}
\hline th & ess & nity & \\
\hline Lokasi & Udara & Banyak & Biaya \\
\hline cukup & tidak & kalangan & untuk \\
\hline strateg & begitu & tamu & tamu \\
\hline is & bersih & yang & yang \\
\hline karena & karena & datang & mengin \\
\hline berdek & berada & untuk & ap \\
\hline atan & di & mengina & lumaya \\
\hline denga & perkota & $\mathrm{p}$, & $n$ \\
\hline$n$ & an. & berbisnis, & mahal \\
\hline fasilita & & makan, & karena \\
\hline$s$ & & dll. & lokasi \\
\hline umum & & & yang \\
\hline dan & & & strategi \\
\hline mudah & & & s. \\
\hline diakse & & & \\
\hline 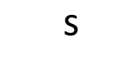 & & & \\
\hline Kebisin & Gedung & Panas & Kualitas \\
\hline gan & menda & matahari & dan \\
\hline tidak & pat & dapat & biaya \\
\hline menga & mataha & digunaak & untuk \\
\hline nggu & ri saat & an & materia \\
\hline aktivit & sore & sebagai & I harus \\
\hline as & sehingg & cahaya & diperha \\
\hline pengg & a & alami & tikan \\
\hline una & bagian & untuk & karena \\
\hline hotel & kiri & perancan & cender \\
\hline karena & gedung & gan & ung \\
\hline lokasi & harus & hotel. & mahal. \\
\hline
\end{tabular}

\begin{tabular}{|c|c|l|l|}
\hline hotel & mengg & \\
tdak & unakan & & \\
langsu & kaca & \\
ng di & yang & & \\
sebela & meman & & \\
h & tulkan & & \\
jalan. & panas. & & \\
\hline
\end{tabular}

Tabel 1.1 Analisis SWOT pada hotel Doubeltree

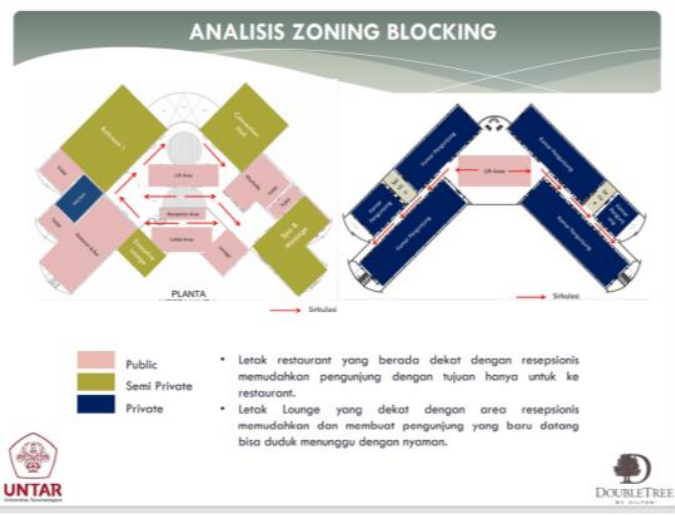

Gambar 1.3 Analisis Zoning Blocking

Alasan mengapa penulis membuat zoning blocking seperti diatas, adalah karena:

1. Letak restaurant yang berada dekat dengan resepsionis memudahkan pengunjung dengan tujuan hanya untuk ke restaurant.

2. Letak lounge yang dekat dengan area resepsionis memudahkan dan membuat pengunjung yang baru datang bisa duduk menunggu dengan nyaman. 
3. Area service yang berada di tengah kamar tamu agar memudahkan serkulasi room service membersihkan kamar tamu.

\subsection{KONSEP DESAIN}

Konsep perancangan interior Hotel Doubletree ini adalah "The Next Level of Comfort." Maksud dari Next Level sendiri adalah peningkatan perancangan interior hotel Doubletree yang memiliki unsur modern, adaptable, sophisticated, dan trendy. Sedangkan comfort sendiri berasal dari salah satu ciri khas Doubletree yang menawarkan seluruh tamu hotel cookies khas buatan Doubletree dan unsur interior yang mengandung suasana comfy dan warm. Tema ini menjadi pedoman dalam perancangan interior Hotel Doubletree untuk menentukan pembagian ruang, pemilihan material, dan warna yang akan digunakan.

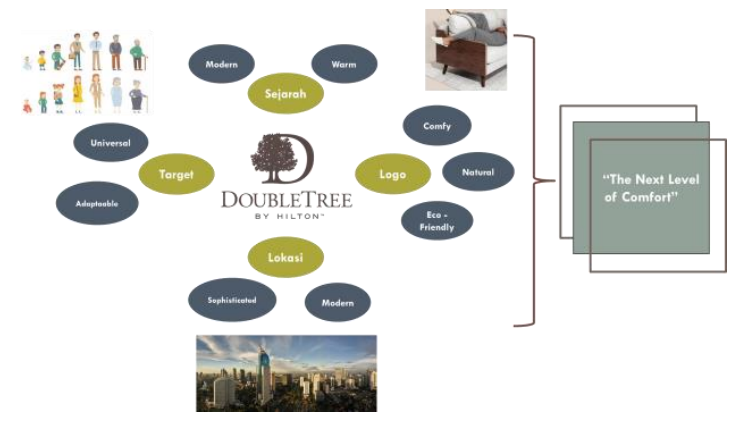

Gambar 1.4 Konsep Tema Hotel Doubletree

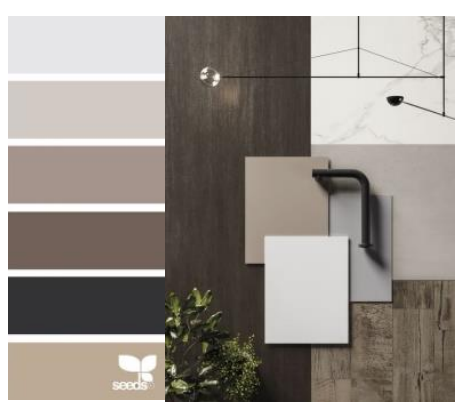

Gambar 1.5 Konsep Warna

Warna yang digunakan pada interior hotel adalah warna-warna yang hangat dengan tujuan untuk memberikan kesan yang hangat dan nyaman bagi para pengunjung. Warna-warna yang digunakan, antara lain:

a. Warna putih: Memberi kesan luas dan memberikan rasa kenyamanan. Selain itu putih juga mencerminkan kebersihan, kebaikan, kesederhanaan, dan damai.

b. Warna coklat: Memberikan kesan hangat, kenyamanan, 
dan mencerminkan suasana yang teduh.

c. Warna

hitam:

Melambangkan

perlindungan. Menampilkan

perspektif dan kedalaman.
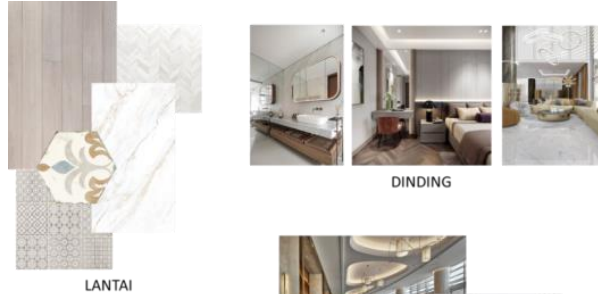

DINDING

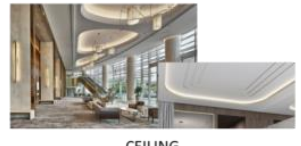

Gambar 1.6 Konsep Lantai, Dinding, dan Ceiling

Lantai pada area lobby menggunakan granit tiles dengan warna yang dominan putih, furniture - furniture yang ecofriendly dengan gaya yang simple namun modern, serta rugs untuk memberikan kesan yang nyaman, dan lampu yang bergaya modern untuk memberikan kesan modern. Sedangkan pada area kamar pengunjung, lantai menggunakan vinyl.

Dinding pada area lobby akan dominan menggunakan cat tembok warna putih dan sentuhan granite tile dengan tujuan memberikan bersih, nyaman, simple namun tetap memiliki kesan modern pada saat bersamaan di dalam interior hotel. Material yang digunakan pada plafond dihotel baik pada area lobby maupun kamar tidur ialah gypsum. Ceiling dibuat penurunan dengan menggunakan hidden lamp.

\subsection{KEPUTUSAN DESAIN}

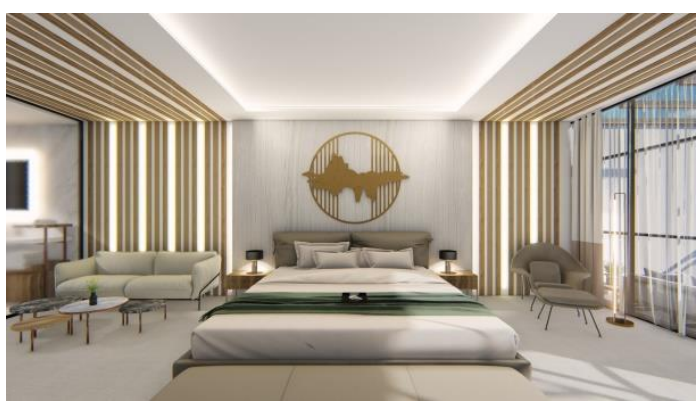

Gambar 1.7 Perspektif Kamar Suite Lounge King

Suasana yang ingin diciptakan pada kamar Suite Lounge King adalah warm and cozy. Material yang digunakan pada bagian belakang ranjang adalah granit dengan kisi kisi kayu dan lampu LED sebagai indirect lamp. Ranjang pada Suite Lounge King menggunakan ranjang SweetDreams yang di produksi oleh Doubletree sendiri. Pencahayaan yang ada di dalam interior kamar Suite Lounge berasal dari cahaya 
matahari dan lampu downlight yang bewarna neutral white.

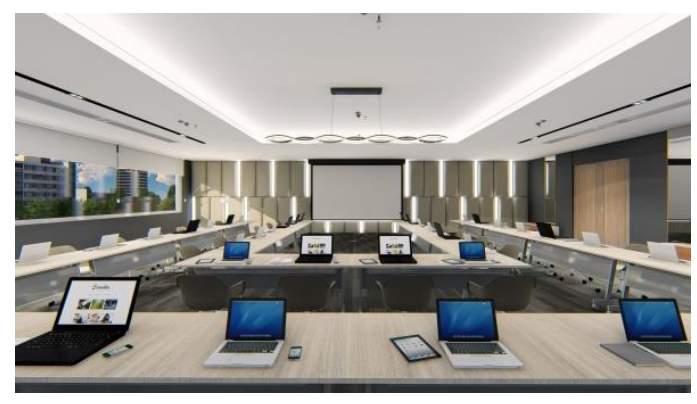

Gambar 1.8 Perspektif Meeting Room

Suasana yang ingin diciptakan pada meeting room adalah focus and adaptable. Pada bagian depan meeting room menggunakan padded wall sebagai salah satu elemen akustik pada meeting room agar mencegah suara dari luar / dalam masuk ke dalam / keluar ruangan dan terdapat lampu LED di sela sela padded wall untuk menambah terang ruangan. Meja yang digunakan pada meeting room adalah meja folding yang berukuran $170 \mathrm{~cm} \times 60 \mathrm{~cm}$ dan sarana untuk presentasi pada meeting room adalah menggunakan screen dan projector. Pencahayaan pada ruang meeting berasal dari cahaya matahari dan lampu downlight yang bewarna cool white.

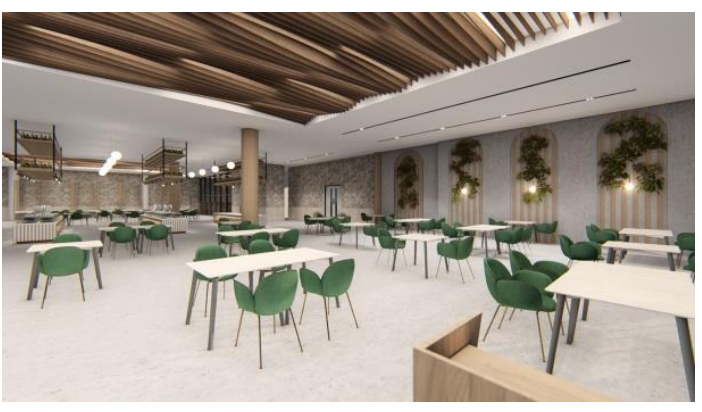

Gambar 1.9 Perspektif Restaurant (View 1)

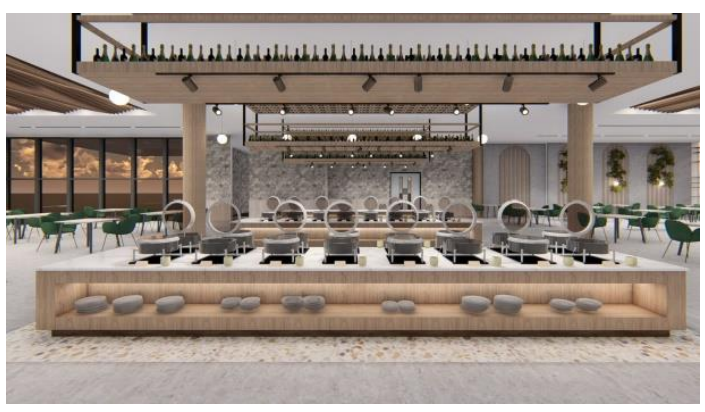

Gambar 2.0 Perspektif Restaurant (View 2)

Suasana yang ingin diciptakan pada restaurant ini adalah fresh and natural. Lantai pada restaurant menggunakan homogenous tiles dengan stone effect. Furniture meja dan kursi pada restaurant mempunyai kapasitas untuk 200 orang. Pencahayaan pada restaurant berasal dari cahaya matahari, lampu downlight yang bewarna neutral white, lampu dinding, spotlight, dan lampu gantung pada area meja 


buffet. Material -
material di
restaurant juga dominan
menggunakan kayu agar
memberikan kesan natural dan
aksen warna hijau untuk
memberikan kesan fresh pada
interior ruangan.

\section{KESIMPULAN}

Perancangan sebuah hotel perlu mempertimbangkan dua aspek utama, yaitu efisiensi dan kenyamanan. Dua aspek ini secara keseluruhan akan mempengaruhi keputusan sebuah rancangan hotel. Perancangan ini menjelaskan betapa pentingnya peran interior dalam kehidupan manusia sebagai penggunanya. Pada interior Hotel Doubletree fokus perancangan di tekankan pada kamar hotel tipe Suite Lounge King, restaurant, dan meeting room. Fasilitas pada hotel Doubletree meliputi kamar Deluxe Twin \& King, Suite Lounge King, Suite Penthouse King, Spa \& Massage, Gym, Kids Club, Swimming Pool, Meeting Room, dan Restaurant. Konsep tema yang didapatkan adalah hasil dari analisis makro, mikro, identitas hotel, besaran ruang, zoning blocking, sirkulasi, dan citra. Tema "The Next Level of Comfort" ini menjadi pedoman untuk meningkatkan kualitas dan gaya desain interior hotel Doubletree. Konsep pada setiap ruang disesuaikan dengan kebutuhan dan kenyamanan penggunanya agar memaksimalkan kualitas dan kenyamanan dari peningkatan perancangan hotel Doubletree.

\section{DAFTAR PUSTAKA}

Kilmer, R., \& Kilmer, W. O. (2014). Designing Interior. New Jersey: John Wiley \& Sons, Inc.

Kliment, Stephen. (2001). Building Type Basics for Hospitality Facilities. Canada: John Wiley \& Sons Inc.

Lawson, Fred. (1996). Hotels and Resorts Planning Design and Refurbishment. 
Fakultas Seni Rupa dan Desain - Universitas Tarumanagara

Emmanuella Suryady, Noeratri Andanwerti, Silvia Meliana; Halaman 68 - 77

London: Butterworth

Architecture

Nurfadilah, Citra \& Rachmaniyah,

Nanik. (2016). Redesain

Interior Hotel Bisnis.

JURNAL SAINS DAN SENI

ITS, Vol. 5, No.2, 2337-3520.

Sugiyono. (2009). Metodologi

Penelitian Kuantitatif,

Kualitatif dan R\&D. Bandung:

Alfabeta.

https://www.hilton.com/en/hotels/j

ktdidi-doubletree-jakarta-

diponegoro/gallery 